Research Article

\title{
Performance Assessment on Fiberglass-Polyester Paving Mat Being Applied in Asphalt Mixture Complex
}

\author{
Wei Gang ${ }^{1}$ and Mao Xinbo (D) $^{2}$ \\ ${ }^{1}$ School of Civil Engineering, Chongqing Jiaotong University, Chongqing, China \\ ${ }^{2}$ Science and Technology Management Center, Chongqing Chongjiao Renewable Resources Development Co., Ltd., \\ Chongqing, China
}

Correspondence should be addressed to Mao Xinbo; maoxinbo_19930303@163.com

Received 3 June 2020; Accepted 26 June 2020; Published 20 July 2020

Academic Editor: Xue Luo

Copyright (C) 2020 Wei Gang and Mao Xinbo. This is an open access article distributed under the Creative Commons Attribution License, which permits unrestricted use, distribution, and reproduction in any medium, provided the original work is properly cited.

\begin{abstract}
This paper mainly studies performances of the asphalt mixture complex paved with fiberglass-polyester paving mat. We have examined the performances of the complex paved with fiberglass-polyester paving mat by measuring assessment indexes of the asphalt mixture complex such as low-temperature crack resistance, reinforcement strength, soaking shear performance, and fatigue performance and found that a layer of fiberglass-polyester paving mat between the base cement concrete and the topping asphalt mixture can effectively enhance performances of the asphalt mixture complex. First, the bending test and the cleavage test show that complex test pieces paved with fiberglass-polyester paving mat have better flexibility and carrying capacity, thus delaying emergence and extension of reflection cracks in the topping asphalt mixture. Second, the stress control fatigue test and the strain control fatigue test show that complex test pieces paved with fiberglass-polyester paving mat can remarkably prolong fatigue life of the complex, thus prolonging service life of the asphalt pavement. Finally, the soaking shear test and the shear fatigue test show that compared with waterproof roll and glassfiber grid, fiberglass-polyester paving mat can improve shear resistance of the complex test piece more effectively and enhance its durability.
\end{abstract}

\section{Introduction}

With rapid development of construction of express highways, asphalt concrete pavements have been widely studied and applied [1]. However, as vehicle load and service life increase, damages of express highways constructed in early stages or recently are becoming increasingly aggravate and an increasing number of pavements are facing onerous repair works.

Reflection crack is one of the damages for asphalt pavements. Reflection crack can mainly be classified into loading type crack and nonloading type crack [2]. The loading type crack mainly refers to fatigue crack caused by vehicles, which will directly destroy the topping asphalt mixture. The nonloading type crack includes low-temperature shrinkage crack of the topping asphalt mixture and shrinkage crack of the semirigid base. Of them, reflection crack caused by base cleavage is the most serious. To eliminate these distresses, the first thing is to take effective measures of distress treatment towards the base course, for example, enhancing the structural stiffness of lower layers by highly rigid materials $[3,4]$. This construction is difficult and requires large investment but has poor effect. Under combined actions of vehicle load, climate conditions, and rainfalls, reflection crack can aggravate damage degrees of the pavement [5]. The rainwater tends to be detained between the surface course and the base course, leading to bonding failures [6]. At the same time, slurry spurting may occur under the water pressure, lowering carrying capacity of the pavement.

To delay emergence and extension of reflection cracks in asphalt pavements, advanced countries such as America, Britain, Germany, and Canada started to prevent reflection crack [1] with geotextiles at the end of the last century and 
have achieved effect of different degrees. Fiberglass-polyester paving mat is a new-type complex geosynthetics developed after waterproof roll, glassfiber grid, and geotechnical cloth. It is composed of $60 \%$ of glassfiber and $40 \%$ of polyester fiber [7]. It has low shrinkage ratio and good compatibility and chemical stability. It is convenient for construction and does not wrinkle easily. Combined with hot asphalt, it can form a water proof layer, preventing surface rainwater from infiltration and protecting pavement structures from rainwater damages [8-10]. In addition, sandwich materials of the fiberglass-polyester paving mat have strong adhesive performance, which can remarkably improve shear resistance of the base and topping materials and at the same time can enhance flexibility of the pavement structures and fatigue performance and carrying capacity of the pavement $[11,12]$.

This paper mainly studies effect and performance of fiberglass-polyester paving mat in construction of the asphalt pavement. By a large quantity of indoor tests, it is proved that application of fiberglass-polyester paving mat can enhance flexibility and shear resistance of the asphalt mixture complex and prolong its fatigue life. For complex test pieces composed of sandwich materials and topping asphalt mixture, this study has examined low-temperature crack resistance of the complex through the low-temperature bending test, assessed reinforcement strength performance of the complex through the ultimate bending test and cleavage strength test and explored fatigue performance of the complex through the stress control fatigue test and strain control fatigue test. For complex test pieces composed of the base cement concrete, sandwich materials, and topping asphalt mixture, this study has assessed water stability and fatigue durability of the complex through the soaking shear test and shear fatigue test, respectively.

\section{Material and Method}

2.1. Constituent Materials of the Asphalt Complex. Based on constituents of traditional asphalt pavements, sandwich materials are paved between the semirigid base and the asphalt mixture topping with the anticipation to enhance adhesive performance between the semirigid base and the asphalt mixture topping, lower diffusion rate of reflection crack from the base course to the surface course, and prolong service life of the asphalt pavement. The asphalt mixture complex studied in this study is mainly composed of the semirigid base, the sandwich materials, and the asphalt mixture topping.

2.1.1. Base Materials. According to constituents of the asphalt pavement, the $50 \mathrm{~mm}$ thick C40 cement concrete has been chosen as the semirigid base for the asphalt complex. The proportion of cement to concrete is designed according to the test regulation. The major parameters are listed in Table 1.

2.1.2. Adhesive Material. Adhesive material is one of the constituents of the sandwich materials. As there is an adhesive between the base course and the fiberglass-polyester paving mat, it is waterproofing and can enhance shear strength of the asphalt complex, maintaining the synergy stability of pavement structure [13]. In this study, hot $\mathrm{AH}-$ 70\# matrix asphalt is selected as adhesive material between the base material and the fiberglass-polyester paving mat. The coating weight is $1.0 \mathrm{~kg} / \mathrm{m}^{2}$. The major technical parameters are listed in Table 2.

2.1.3. Fiberglass-Polyester Paving Mat. As a reflection crack proofing material is widely used in asphalt pavements, fiberglass-polyester paving mat can form sandwich materials with adhesive material. Fiberglass-polyester paving mat is well compatible with the topping asphalt mixture and can form a compact waterproof layer. In addition, it has good ductility. The fiberglass-polyester paving mat adopted in this study is TruPave fiberglass-polyester paving mat produced by Owens Corning Company of America. Its physical and mechanical property indexes are listed in Table 3.

2.1.4. Asphalt Mixture. The topping material of the asphalt complex is AC-20I asphalt mixture, with its composite gradation being listed in Table 4 . The property of aggregate has a great influence on the strength of mixture [14]. The aggregate is limestone with the maximum nominal particle size $19 \mathrm{~mm}$. The mineral powder is grinded from the same limestone with adding mass fraction $2 \%$. The asphalts are the above matrix asphalt (Table 2) and SBS-modified asphalt. The optimal asphalt amount is $4.5 \%$. The technical parameters of the SBS-modified asphalt are listed in Table 5.

\subsection{Performance Assessment Method on Asphalt Complex.} In order to assess performances of fiberglass-polyester paving mat being applied to asphalt pavement construction, this study has assessed comprehensive performances of the asphalt complex through testing low-temperature crack resistance, reinforcement strength, soaking shear performance, and fatigue performance of the asphalt complex.

\subsubsection{Shear Test for Low-Temperature Immersion in} Composite. This study adopts the shear test for low-temperature immersion in composite to assess low-temperature crack resistance of the asphalt mixture complex. As shown in Figure 1, it cuts the newly prepared asphalt mixture of $300 \mathrm{~mm} \times 300 \mathrm{~mm} \times 50 \mathrm{~mm}$ into trabecula test pieces of $35 \mathrm{~mm} \times 30 \mathrm{~mm} \times 250 \mathrm{~mm}$ (span length $200 \mathrm{~mm} \pm 0.5 \mathrm{~mm}$ ) and removes floating dust from the bottom after natural drying. A fiberglass-polyester paving mat of the same size at the bottom of the trabecula test piece is paved with adhesive materials. Before the test, it is cured at the test temperature for $6 \mathrm{~h}$. The test equipment is Material Test System (MTS). The test temperature is $-10^{\circ} \mathrm{C}$, and the loading rate is $50 \mathrm{~mm} /$ $\mathrm{min}$. Indexes for the low-temperature bending test include fracture load $\left(P_{\mathrm{B}}\right)$, midspan deflection $(\mathrm{d})$, flexural-tensile strength $\left(R_{\mathrm{B}}\right)$, maximum flexural-tensile strain $\left(\varepsilon_{\mathrm{B}}\right)$, bending stiffness modulus $\left(S_{\mathrm{B}}\right)$, and strain energy density $\left(U_{\varepsilon}\right)$ of the test piece. 
TABLE 1: Major parameters of base cement concrete.

\begin{tabular}{|c|c|c|c|c|c|c|c|c|}
\hline \multirow{2}{*}{$\begin{array}{l}\text { Maximum particle diameter of } \\
\text { aggregates } / \mathrm{mm}\end{array}$} & \multirow{2}{*}{ Cement strength/MPa } & \multirow{2}{*}{$\begin{array}{l}\text { Water-cement } \\
\text { ratio }\end{array}$} & \multirow{2}{*}{$\begin{array}{l}\text { Sand ratio } \\
(\%)\end{array}$} & \multirow{2}{*}{ Slump/mm } & \multicolumn{4}{|c|}{$1 \mathrm{~m}^{3}$ ingredient amount $/ \mathrm{kg}$} \\
\hline & & & & & Water & Cement & Sand & Stone \\
\hline 16 & 42.5 & 0.45 & 33 & $30 \sim 50$ & 210 & 468 & 521 & 1201 \\
\hline
\end{tabular}

TABLE 2: Technical parameters of AH-70\# matrix asphalt.

\begin{tabular}{|c|c|c|}
\hline & Test item & Test value \\
\hline & $\begin{array}{c}\text { Needle penetration }\left(100 \mathrm{~g}, 25^{\circ} \mathrm{C}, 5 \mathrm{~s}\right)(0.1 \mathrm{~mm}) \\
\text { Ductility }\left(10^{\circ} \mathrm{C}, 5 \mathrm{~cm} / \mathrm{min}\right) \mathrm{cm} \\
\text { Ductility }\left(15^{\circ} \mathrm{C}, 5 \mathrm{~cm} / \mathrm{min}\right) \mathrm{cm} \\
\text { Softening point, }{ }^{\circ} \mathrm{C} \\
\text { Flash point }(\mathrm{COC}),{ }^{\circ} \mathrm{C} \\
\text { Solubility of trichloroethylene, } \% \\
\text { Density }\left(\mathrm{g} \cdot \mathrm{cm}^{-3}\right)\end{array}$ & $\begin{array}{c}74 \\
>100 \\
>150 \\
47.2 \\
296 \\
99.97 \\
1.003\end{array}$ \\
\hline Result of the thin-film oven test & $\begin{array}{c}\text { Ductility }\left(10^{\circ} \mathrm{C}, 5 \mathrm{~cm} / \mathrm{min}\right), \mathrm{cm} \\
\text { Ductility }\left(15^{\circ} \mathrm{C}, 5 \mathrm{~cm} / \mathrm{min}\right), \mathrm{cm} \\
\text { Needle penetration }\left(100 \mathrm{~g}, 25^{\circ} \mathrm{C}, 5 \mathrm{~s}\right)(0.1 \mathrm{~mm}) \\
\text { Mass variation }(\%)\end{array}$ & $\begin{array}{c}9.2 \\
>100 \\
66 \\
0.0263\end{array}$ \\
\hline
\end{tabular}

Table 3: Performance indexes of TruPave fiberglass-polyester paving mat.

\begin{tabular}{lr}
\hline Test item & Test value \\
\hline Mass area ratio $\left(\mathrm{g} \cdot \mathrm{m}^{-2}\right)$ & 136 \\
Thickness $(2 \mathrm{kPa}), \mathrm{mm}$ & 0.69 \\
Longitudinal tensile strength $\left(\mathrm{kN} \cdot \mathrm{m}^{-1}\right)$ & 8.80 \\
Transverse tensile strength $\left(\mathrm{kN} \cdot \mathrm{m}^{-1}\right)$ & 8.12 \\
Transverse ductility, \% & 3.97 \\
Longitudinal ductility, \% & 3.89 \\
Mullen burst strength, $\mathrm{kPa}$ & 395 \\
Asphalt absorptive amount $\left(\mathrm{L} / \mathrm{m}^{2}\right)$ & 1.14 \\
Melting point, ${ }^{\circ} \mathrm{C}$ & $>230$ \\
\hline
\end{tabular}

TABLE 4: Composite gradation of AC-20I asphalt mixture.

\begin{tabular}{lllllllllllll}
\hline Screen size $/ \mathrm{mm}$ & 26.5 & 19 & 16 & 13.2 & 9.5 & 4.75 & 2.36 & 1.18 & 0.6 & 0.3 & 0.15 & 0.075 \\
\hline Passing rate (\%) & 100 & 95 & 85 & 71 & 61 & 41 & 30 & 22.5 & 16 & 11 & 8.5 & 5 \\
\hline
\end{tabular}

TABLE 5: Technical parameters of the SBS-modified asphalt.

\begin{tabular}{|c|c|c|}
\hline & Test item & Test value \\
\hline & Needle penetration $\left(100 \mathrm{~g}, 25^{\circ} \mathrm{C}, 5 \mathrm{~s}\right)(0.1 \mathrm{~mm})$ & 57 \\
\hline & PI value & 0.02 \\
\hline & Ductility $\left(5^{\circ} \mathrm{C}, 5 \mathrm{~cm} / \mathrm{min}\right), \mathrm{cm}$ & 41 \\
\hline & Softening point, ${ }^{\circ} \mathrm{C}$ & 78 \\
\hline & Flash point $(\mathrm{COC}),{ }^{\circ} \mathrm{C}$ & 298 \\
\hline & Solubility of trichloroethylene, $\%$ & 99.81 \\
\hline & Dynamic viscosity $\left(135^{\circ} \mathrm{C}\right)(\mathrm{Pa} \cdot \mathrm{s})$ & 2.263 \\
\hline & Elastic recovery $\left(25^{\circ} \mathrm{C}\right), \%$ & 94 \\
\hline \multirow{3}{*}{ Result of the thin-film oven test } & Ductility $\left(5^{\circ} \mathrm{C}, 5 \mathrm{~cm} / \mathrm{min}\right), \mathrm{cm}$ & 23.4 \\
\hline & Needle penetration ratio $\left(25^{\circ} \mathrm{C}\right), \%$ & 76.79 \\
\hline & Mass variation, $\%$ & 0.0263 \\
\hline
\end{tabular}

2.2.2. Reinforcement Strength Test. This study adopts the ultimate bending test and the cleavage strength test to assess strength performance of the asphalt mixture complex. Test pieces to be adopted in the ultimate bending test will be prepared in the same procedure as in Section 2.2.1. The test equipment is still Material Test System (MTS). The test temperature is $15^{\circ} \mathrm{C}$, and the loading rate is $50 \mathrm{~mm} / \mathrm{min}$. In the cleavage strength test, the load of a circular layer of a certain width is applied to the cylinder test piece of the specified size, making the test piece split until being destroyed. Then, we will measure and compare technical parameters such as cleavage strength and stiffness failure 


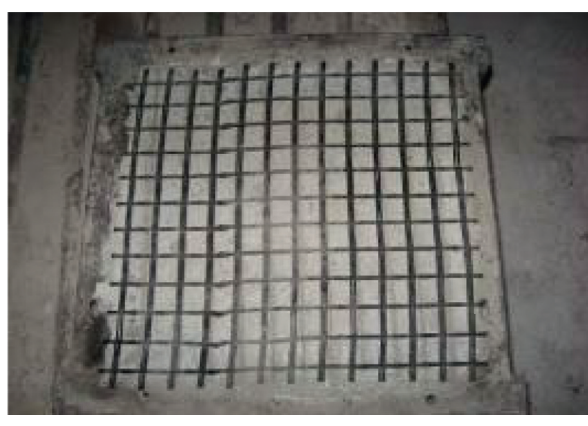

(a)

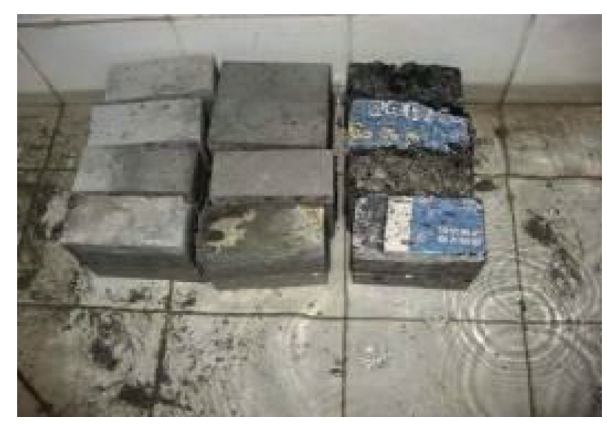

(b)

Figure 1: Shear test for low-temperature immersion: (a) fiberglass grille arrangement and (b) water immersion.

modulus of different complex test pieces. We take the $\Phi 101.6 \times 63.5$ Marshal test piece with optimal bitumenaggregate ratio and apply a layer of adhesive material on the external surface of the test piece after demoulding. By reference to the geotextile cleavage test conducted at the University of Florida [15], we wrap a layer of fiberglasspolyester paving mat around the test piece and conduct the cleavage strength test at $15^{\circ} \mathrm{C}$. Indexes for the ultimate bending test include fracture load $\left(P_{\mathrm{B}}\right)$, midspan deflection $(d)$, flexural-tensile strength $\left(R_{\mathrm{B}}\right)$, maximum flexural-tensile strain $\left(\varepsilon_{\mathrm{B}}\right)$, and bending stiffness modulus $\left(S_{\mathrm{B}}\right)$ of the test piece. Indexes for the cleavage strength test include fracture load $\left(P_{\mathrm{T}}\right)$, loading time $(\mathrm{t})$, cleavage tensile strength $\left(R_{\mathrm{T}}\right)$, and stiffness failure modulus $\left(\varepsilon_{\mathrm{T}}\right)$ of the test piece.

2.2.3. Soaking Shear Performance Test. This study has assessed water stability of fiberglass-polyester paving mat (TP), waterproof roll (WP), and glassfiber grid (FG) by interlayer soaking shear strength. First, a cement concrete base is prepared in the size of $300 \mathrm{~mm} \times 300 \mathrm{~mm} \times 50 \mathrm{~mm}$. After initial setting, galling treatment is made to its surface. After curing for $28 \mathrm{~d}$, floating dust is removed from the surface and it is dried in natural conditions. Then, adhesive material is applied to the surface of the cement concrete base and the fiberglass-polyester paving mat is paved. Finally, a $50 \mathrm{~mm}$ thick asphalt mixture topping is formed with the rolling method upon the fiberglass-polyester paving mat and it is placed at room temperature for $48 \mathrm{~h}$. After demoulding, we will get an asphalt complex test piece of $300 \mathrm{~mm} \times 300 \mathrm{~mm} \times 100 \mathrm{~mm}$ (thickness of the sandwich materials is omitted). We form complex test pieces containing these three crack-resistant materials, respectively, and cut them into cubic test pieces of $100 \mathrm{~mm} \times 100 \mathrm{~mm} \times 100 \mathrm{~mm}$. In order to simulate actual conditions of the asphalt complex in a humid environment, we soak the asphalt complex test piece in water for $0 \mathrm{~d}, 5 \mathrm{~d}$, $10 \mathrm{~d}, 15 \mathrm{~d}, 20 \mathrm{~d}$, and $25 \mathrm{~d}$, respectively. The Universal Testing Machine (UTM) is adopted to perform the shear test towards the soaked test pieces. The interlayer shear strength can be calculated with the following formula:

$$
\tau=\frac{F}{A} \sin \alpha,
$$

where $\tau$ is the shear strength (MPa), $\mathrm{F}$ is the vertical loading force $(\mathrm{N}), \mathrm{A}$ is the contact area of the shear front $\left(\mathrm{m}^{2}\right)$, and $\alpha$ is the oblique shear angle $\left(40^{\circ}\right)$.

2.2.4. Fatigue Assessment. This study has assessed fatigue performance of the asphalt mixture complex mainly through the stress control fatigue test, strain control fatigue test, and shear fatigue test. Test pieces to be used in the stress control fatigue test will be prepared according to the procedure in Section 2.2.1. The temperature load exists in the three-dimensional space of the pavement, and compared with the direct load, the temperature load is more uniform in the three-dimensional direction, so the pavement is mainly subjected to the fatigue of the upper and lower and the braking force direction. The three-dimensional performance test can be simplified to the two-dimensional fatigue performance test using the Marshal specimen, see Figure 2. Compared with live load, the braking force is smaller in order of magnitude, so the action of driving load can be approximately simulated by the beam-bending test method. Through cutting, we can get asphalt mixture trabecula test pieces of $35 \mathrm{~mm} \times 35 \mathrm{~mm} \times 250 \mathrm{~mm}$ (span length $200 \mathrm{~mm} \pm 0.5 \mathrm{~mm}$ ). After natural drying, remove floating dust from the bottom of the test piece. A fiberglass-polyester paving mat of the same size at the bottom of the trabecula test piece is paved with adhesive material. It is cured for $6 \mathrm{~h}$ at $15^{\circ} \mathrm{C}$. The stress-fatigue test should be performed on the Material Test System (MTS) with stress-strength ratios of $0.2,0.25,0.3,0.35$, and 0.4 , respectively. The loading model is shown in Figure 3. The temperature for the fatigue test is $15^{\circ} \mathrm{C}$. The strain control fatigue test will cut the newly prepared asphalt mixtures of $400 \mathrm{~mm} \times 300 \mathrm{~mm} \times 70 \mathrm{~mm}$ into trabecula test pieces of $381 \mathrm{~mm} \times 635 \mathrm{~mm} \times 50 \mathrm{~mm}$. The strain fatigue test should be performed on the Universal Testing Machine (UTM). The third-point loading method is applied to the test pieces. The loading model is shown in Figure 4. The distance between end pivots is $356 \mathrm{~mm}$. The loading times are taken when the stiffness modulus is $50 \%$ of the initial stiffness modulus as the fatigue failure criterion. The temperature for the fatigue test is $15^{\circ} \mathrm{C}$. Test pieces to be used in the shear fatigue test will be prepared in the same procedure of 2.2.3. We will get complex test pieces of $100 \mathrm{~mm} \times 100 \mathrm{~mm} \times 100 \mathrm{~mm}$ containing the above three 


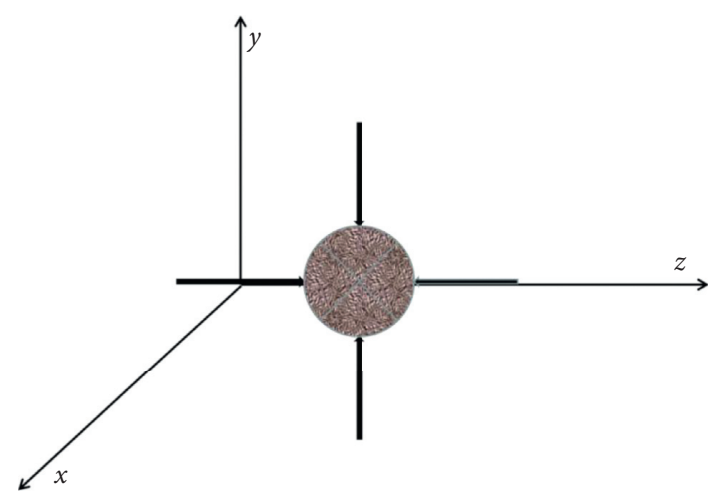

Figure 2: Schematic diagram of the two-dimensional fatigue performance test.

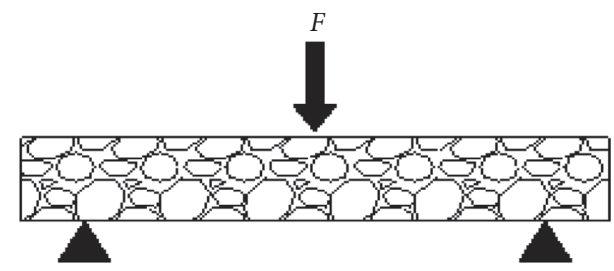

FIgURE 3: Loading model for the MTS test.

crack-resistant materials, respectively. The shear fatigue test should be conducted on a Cooper fatigue tester produced by Cooper Research Technology Company. When the interlayer interface displacement reaches $3 \mathrm{~mm}$, it is regarded as the failure criterion for the shear fatigue test. The loading waveform is sine wave, the loading frequency is $10 \mathrm{HZ}$, and the test temperature is $20^{\circ} \mathrm{C}$. Before the test, keep all the test pieces in an environmental temperature control box for more than 4 hours. The relation is analyzed between fatigue life of the asphalt mixture complex and its stress level by using the regression equation $\lg N_{f}=k-n \lg \sigma$, where $N_{\mathrm{f}}$ and $\sigma$ are the loading times and loading stress, respectively, $k$ and $n$ are the regression constants, $k$ is the intercept of the imitative straight line, and $n$ is its slope.

\section{Result and Discussion}

3.1. Low-Temperature Crack Resistance. This study has compared low-temperature crack resistances of the following four asphalt mixture complexes: matrix asphalt mixture without fiberglass-polyester paving mat (NTPMAM), matrix asphalt mixture with fiberglass-polyester paving mat (YTP-MAM), SBS-modified asphalt mixture without fiberglass-polyester paving mat (NTP-SBSAM), and SBS-modified asphalt mixture with fiberglass-polyester paving mat (YTP-SBSAM). From the results in Table 6, we can know that fiberglass-polyester paving mat has some impact on low-temperature bending performance of the asphalt complex. Especially, it can remarkably enhance lowtemperature crack resistance of the matrix asphalt mixture complex. Ultimate deformation capacity of the asphalt mixture complex at low temperatures reflects low-temperature viscosity and plasticity of viscous-elastic materials.

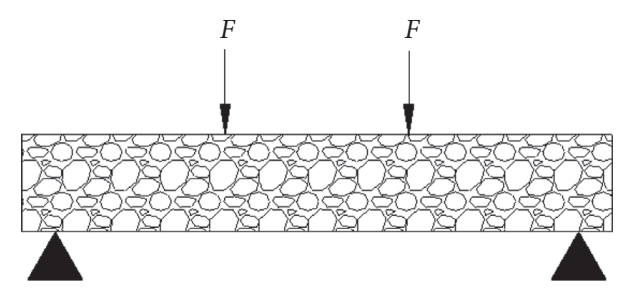

Figure 4: Loading model for the UTM test.

The better the low-temperature flexibility, the better the low-temperature crack resistance. Though the application of fiberglass-polyester paving mat has not remarkably enhanced strength performances of the complex such as carrying capacity and flexural strength, it has evidently improved flexibility of the complex. Increase of midspan deflection and flexural-tensile strain and decrease of stiffness modulus can enhance antideformability of the complex. Increase of strain energy density can suitably lower sensibility of the complex towards loads and enhance elastic performance of the complex. In this way, lowtemperature crack resistance of the complex can also be enhanced.

\subsection{Reinforcement Strength Performance}

3.2.1. Ultimate Bending Test. The results of the ultimate bending test for test pieces of the four asphalt mixture complexes reflect their bending failure mechanical properties, respectively. From the data in Table 7, we can know that tendencies presented in the ultimate bending test for the complex are basically consistent with those presented in the low-temperature bending test. Application of fiberglasspolyester paving mat has increased carrying capacity and flexural strength of the two asphalt mixture complexes and at the same time has increased midspan deflection and maximum flexural-tensile strain and lowered stiffness modulus. So, it can satisfactorily improve bending resistance of the complexes and enhance their mechanical property and elasticity. In actual engineering applications, it can effectively reduce stress concentration at pavement junctions or cracks and reduce extension and upward reflection of cracks in the pavement.

3.2.2. Cleavage Strength Test. The result of the cleavage strength test for Marshal test pieces of the four asphalt mixture complexes is presented in Table 8. Application of fiberglass-polyester paving mat has slightly reduced carrying capacity and cleavage tensile strength of two complexes but evidently prolonged loading time of the two complexes by $135.9 \%$ and $61.4 \%$, respectively, and at the same time reduced stiffness failure modulus of the complexes. The cleavage strength test proves that fiberglass-polyester paving mat has little impact on mechanical property of the asphalt mixture complex, but it can remarkably enhance its bearing tenacity, thus delaying emergence and diffusion of reflection cracks and prolonging service life of roads. 
TABLE 6: Result of the low-temperature bending test.

\begin{tabular}{lccccc}
\hline Type of asphalt mixtures & $P_{B}(\mathrm{~N})$ & $D(\mathrm{~mm})$ & $R_{B}(\mathrm{MPa})$ & $\varepsilon_{B}$ & $S_{B}(\mathrm{MPa})$ \\
\hline NTP-MAM & 3236 & 0.21 & 7.77 & $1.57 \times 10^{-3}$ & 5065.02 \\
YTP-MAM & 3630 & 0.32 & 8.71 & $2.43 \times 10^{-3}$ & 3572.58 \\
NTP-SBSAM & 3831 & 0.25 & 9.20 & $1.85 \times 10^{-3}$ & 5.98 \\
YTP-SBSAM & 3854 & 0.33 & 9.23 & $2.47 \times 10^{-3}$ & 36.66 \\
\hline
\end{tabular}

TABLE 7: Result of the ultimate bending test.

\begin{tabular}{lcccc}
\hline Type of asphalt mixtures & $P_{B}(\mathrm{~N})$ & $\mathrm{D}(\mathrm{mm})$ & $R_{B}(\mathrm{MPa})$ & $\mathcal{E}_{B}$ \\
\hline NTP-MAM & 832 & 1.21 & 6.79 & $6.37 \times 10^{-3}$ \\
YTP-MAM & 957 & 2.09 & 7.81 & $10.99 \times 10^{-3}$ \\
NTP-SBSAM & 840 & 2.40 & 6.86 & $12.59 \times 10^{-3}$ \\
YTP-SBSAM & 1008 & 3.39 & 8.23 & $17.79 \times 10^{-3}$ \\
\hline
\end{tabular}

TABLE 8: Result of the cleavage strength test.

\begin{tabular}{lcccc}
\hline Type of asphalt mixtures & $P_{T}(\mathrm{kN})$ & $t(\mathrm{~s})$ & $R_{T}(\mathrm{MPa})$ & $\varepsilon_{T}(\mathrm{MPa})$ \\
\hline NTP-MAM & 12.325 & 1.56 & 1.208 & 653 \\
YTP-MAM & 11.024 & 3.68 & 1.080 & 208 \\
NTP-SBSAM & 16.863 & 2.23 & 1.669 & 512 \\
YTP-SBSAM & 14.404 & 3.60 & 1.426 & 311
\end{tabular}

3.3. Soaking Shear Performance. During the construction process of the asphalt pavement, it is hard to avoid emergence of local pores. So, it is hard to eliminate downward infiltration of surface water and upward infiltration of underground water, which may cause structural damages of base courses and surface courses under vehicle load conditions and quicken emergence of pavement cracks. Crackresistant materials can provide a continuous and nondeformable waterproof layer for the asphalt pavement and effectively prevent water infiltration. This study has assessed water stability of fiberglass-polyester paving mat (TP), waterproof roll (WP), and glassfiber grid (FG) through the soaking shear test. The relation between soaking time of the complex and its shear strength is presented in Figure 5.

Soaking shear strengths of the complexes containing the three crack-resistant materials all decrease with the prolonging of the soaking time, but compared with complexes containing the other two crack-resistant materials, the complex containing fiberglass-polyester paving mat has higher soaking shear strength. When the soaking time is $25 \mathrm{~d}$, soaking shear strengths of the three complexes have decreased by $47.9 \%, 65.5 \%$, and $64.8 \%$, respectively, and soaking shear strength of the complex containing TP is 1.93 times and 1.72 times those of the complexes containing FG and WP, respectively. Through one linear fitting, we find that the slope absolute value of the complex containing fiberglass-polyester paving mat is the smallest, proving that soaking time has least impact on the fiberglass-polyester paving mat complex, so its water stability is superior to those of the other two complexes. In summary, of the three common complex geotechnical crack-resistant materials, fiberglass-polyester paving mat has better soaking shear performance, so it is conducive to prevention of emergence of pavement cracks caused by water damages.

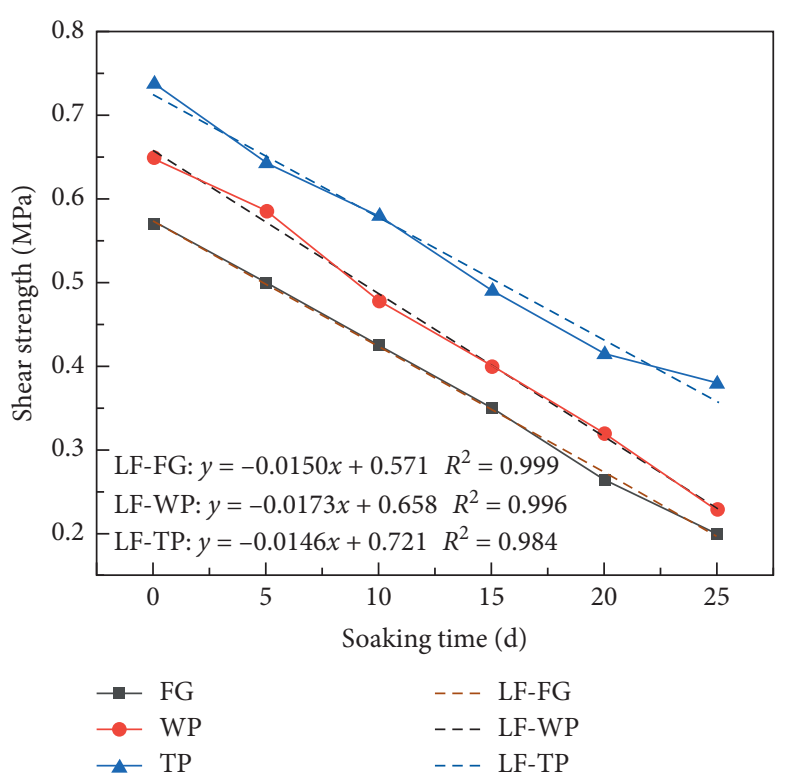

FIgURE 5: Result of the soaking shear test.

\subsection{Fatigue Performance}

3.4.1. Stress Control Fatigue Test. The result of the stress control fatigue test for the four asphalt mixture complexes under different stress-strength ratios is shown in Figure 6. From it, we can see that the same asphalt mixture complexes containing fiberglass-polyester paving mat have longer fatigue life and the prolonging effect is obvious under relatively low stress strength. When the stressstrength ratio is 0.20 , the fatigue life of YTP-MAM is prolonged by $63.6 \%$ as compared with NTP-MAM and the fatigue life of YTP-SBSAM is prolonged by $28.7 \%$ as compared with NTP-SBSAM. As the stress-strength ratio increases, reinforcement effect of the fiberglass-polyester paving mat is gradually weakening. When the stressstrength ratio is 0.40 , fatigue lives of two complexes containing fiberglass-polyester paving mat are prolonged $13.8 \%$ and $14.4 \%$, respectively. So, the prolonging effect is still good. 


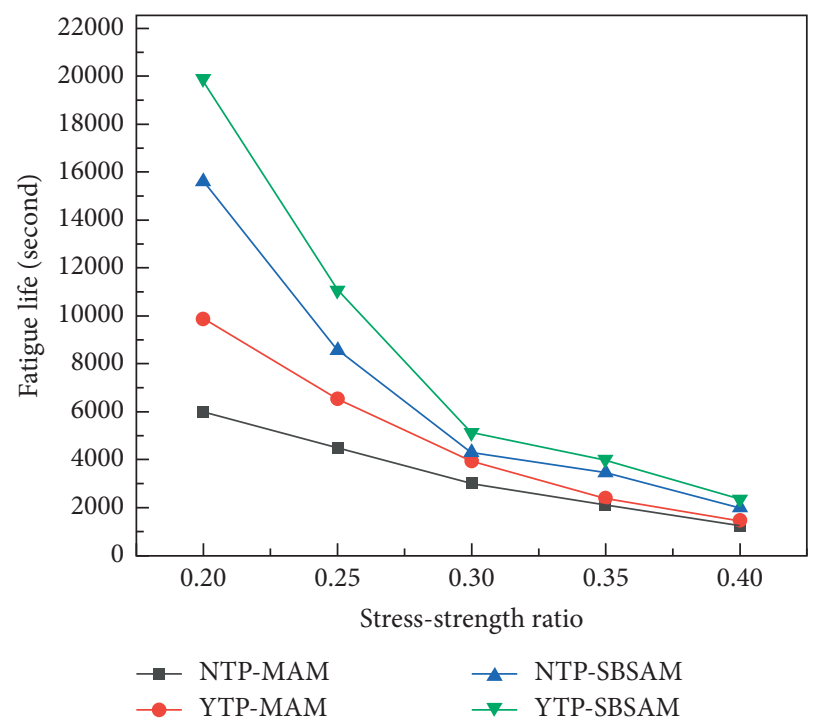

Figure 6: Result of the stress control fatigue test.

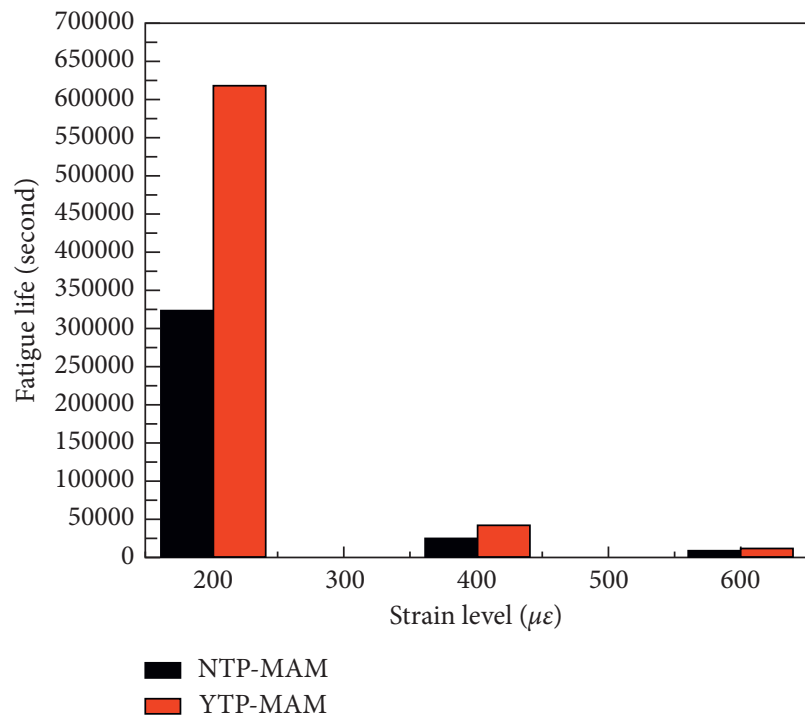

(a)

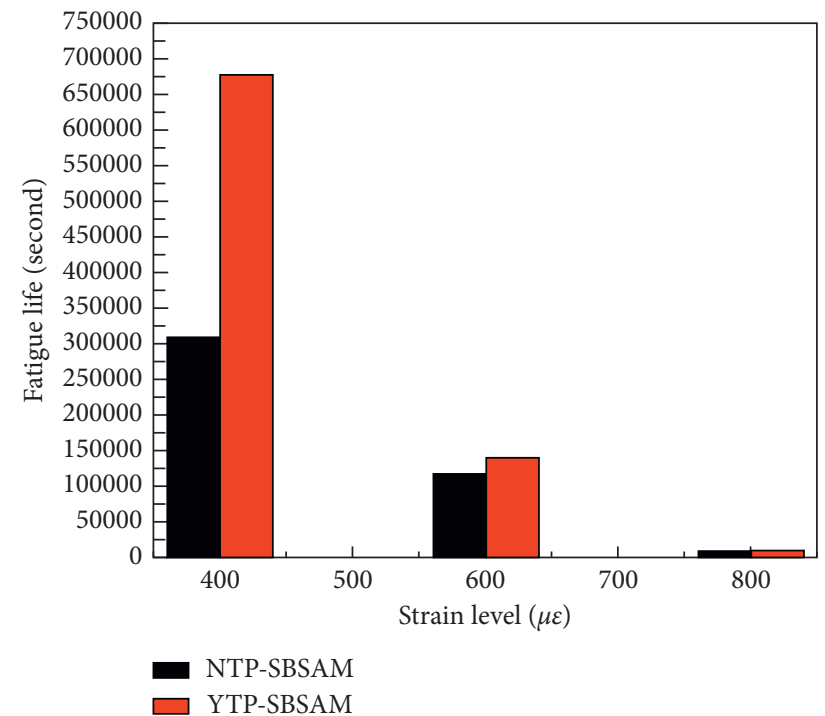

(b)

Figure 7: Result of the strain control fatigue test.

3.4.2. Strain Control Fatigue Test. The result of the stress control fatigue test for the four asphalt mixture complexes under different strain levels is shown in Figure 7. Under three stress levels $(200 \mu \varepsilon, 400 \mu \varepsilon$, and $600 \mu \varepsilon)$, the strain control fatigue test is conducted for the matrix asphalt mixture complex. The result shows that stress level has great impact on fatigue life of the complex, but fiberglass-polyester paving mat can still remarkably prolong fatigue life of the complex. Under the three stress levels, YTP-MAM can prolong fatigue life by $90.9 \%$, $79.2 \%$, and $73.2 \%$, respectively, as compared with NTPMAM, proving that the complex containing fiberglasspolyester paving mat has better strain fatigue resistance.
Under three stress levels $(400 \mu \varepsilon, 600 \mu \varepsilon$, and $800 \mu \varepsilon)$, the strain control fatigue test is conducted for the SBSmodified asphalt mixture complex. The result is consistent with the law from the strain control fatigue test for the matrix asphalt mixture complex. Stress level has great impact on fatigue life of the complex. Under a relatively low stress level, application of fiberglass-polyester paving mat can remarkably prolong fatigue life of the complex. When the stress level is $400 \mu \varepsilon$, the fatigue life of YTPSBSAM is 2.19 times that of NTP-SBSAM. As stress level increases, prolonging effect of fiberglass-polyester paving mat towards fatigue life of the complex is gradually weakening. However, when the stress levels are $600 \mu \varepsilon$ and 


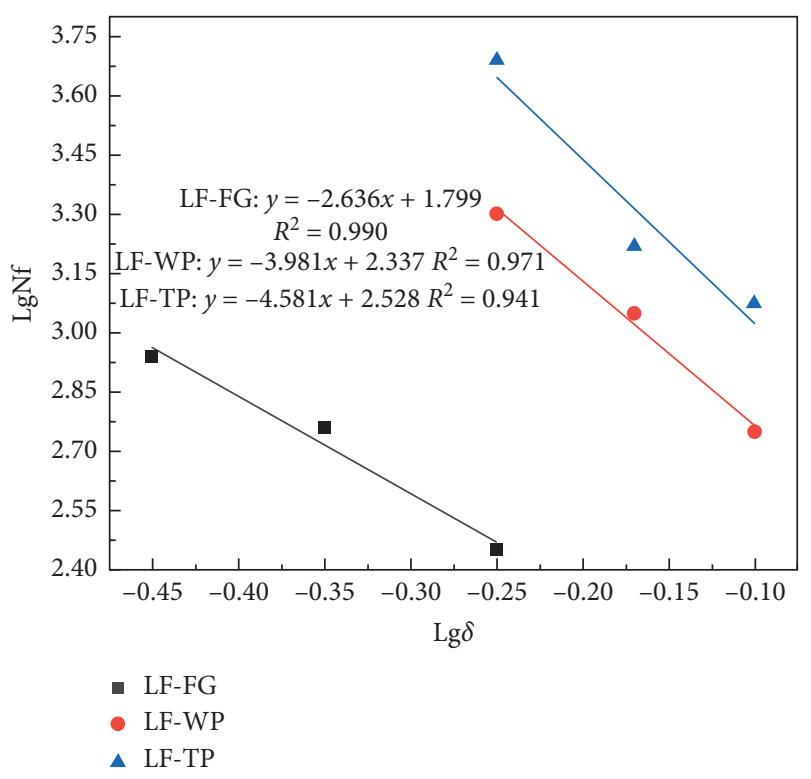

Figure 8: Result of the shear fatigue test.

$800 \mu \varepsilon$, the prolonging proportions can still reach relatively high values of $17.8 \%$ and $13.7 \%$, respectively.

As a constituent of the sandwich materials, fiberglasspolyester paving mat has effectively prolonged stress control fatigue life and strain control fatigue life of the asphalt mixture complex. So, it can enhance creep property of the asphalt pavement, delay emergence and diffusion of reflection cracks, and prolong service life of the asphalt pavement.

3.4.3. Shear Fatigue Test. Fatigue durability of the three crack-resistant materials is assessed through the shear fatigue test. The logarithmic relation between fatigue life $\left(N_{f}\right)$ and stress $(\sigma)$ of the asphalt mixture complexes containing the three crack-resistant materials is shown in Figure 8. Under the dual-logarithm coordinate system, the stress-fatigue life curves of the three interlayer adhesive materials all present good linearity. The result of the shear fatigue test is similar to that of the soaking shear test in 3.3; that is, compared with the other two complexes, the complex containing fiberglasspolyester paving mat has better shear resistance.

The dual-logarithm imitative straight line for the fiberglass-polyester paving mat complex has a large $n$ value, meaning higher sensitivity to stress, but the $k$ value of the imitative straight line is also great. So, under the same stress level, the fiberglass-polyester paving mat complex can still have a relatively long shear fatigue life, presenting better fatigue durability. During the test process, we find that when the interlayer interface displacement of the complex containing fiberglass-polyester paving mat reaches $3 \mathrm{~mm}$, the base cement concrete, sandwich materials, and topping asphalt mixture are still in an adhesive state, and no obvious interlayer separations have been observed. For the complexes containing the other two crack-resistant materials, even if the loading times are few, the interlayer displacement will suddenly reach $3 \mathrm{~mm}$, causing "brittle failure". This indicates that the interlayer has completely lost adhesive property. At this time, the upper and lower layers are actually in a separate state and the waterproof roll or glassfiber grid has lost functions of interlayer adhesiveness and crack proofing.

\section{Conclusion}

In this study, the performances of the asphalt mixture complex paved with fiberglass-polyester paving mat was evaluated by laboratory tests, such as the low-temperature bending test, the ultimate bending test, cleavage strength test, the stress control fatigue test, the strain control fatigue test, the soaking shear test, and the shear fatigue test. From the test data, we can draw the following conclusions.

The low-temperature bending test has compared lowtemperature crack resistances of the four complexes: NTPMAM, YTP-MAM, NTP-SBSAM, and YTP-SBSAM. The result shows that fiberglass-polyester paving mat can enhance carrying capacity and flexural-tensile strength of the complex to some extent. It has an evident effect on increasing midspan deflection, flexural-tensile strain, and strain energy density and decreasing stiffness modulus, so it can further improve flexibility of the complex and enhance its low-temperature crack resistance.

The ultimate bending test and cleavage strength test have compared reinforcement strengths of the four complexes. The result shows that fiberglass-polyester paving mat can not only improve mechanical property and flexibility of the complex but also can delay emergence of damages in the complex. Compared with Marshal test pieces without fiberglass-polyester paving mat, the ultimate loading time can be delayed by $135.9 \%$ and $61.4 \%$, respectively. Therefore, fiberglass-polyester paving mat can effectively delay emergence of reflection cracks in the asphalt pavement, enhance driving comfort, and prolong service life of the road.

The soaking shear test has assessed water stability of three crack-resistant materials: FG, WP, and TP. The result shows that soaking time has great impact on soaking shear strength of the complex, but compared with complexes containing the other two crack-resistant materials, the complex containing fiberglass-polyester paving mat has higher soaking shear strength. After the three complex test pieces are soaked for $25 \mathrm{~d}$, their soaking shear strengths have decreased by $47.9 \%, 65.5 \%$, and $64.8 \%$, respectively, as compared with the unsoaked test pieces. The soaking shear strength of the complex containing TP is 1.93 times and 1.72 times those of the complexes containing FG and WP, respectively. The soaking shear test proves that the complex containing TP has higher water stability as compared with the complex containing WP or TP and can more effectively prevent water damages to pavement structures and extension of pavement cracks.

The stress control fatigue test and strain control fatigue test have assessed fatigue performance of the four complexes. The result shows that application of fiberglasspolyester paving mat can effectively prolong fatigue life of the complex. Though stress-strength ratio and stress level have great impact on fatigue life of the complex, the test 
result still shows that fiberglass-polyester paving mat can effectively prolong fatigue life of the complex. Especially, under a relatively low stress-strength ratio and stress level, the prolonging proportion of fatigue life is very remarkable. When the stress-strength ratio is 0.20 , YTP-MAM can prolong fatigue life by $63.6 \%$ as compared with NTP-MAM and YTP-SBSAM can prolong fatigue life by $28.7 \%$ as compared with NTP-SBSAM. When the stress level is $200 \mu \varepsilon$, YTP-MAM can prolong fatigue life by $90.9 \%$ as compared with NTP-MAM. When the stress level is $400 \mu \varepsilon$, the fatigue life of YTP-SBSAM is 2.19 times that of NTP-SBSAM.

The shear fatigue test has compared fatigue durability of the three crack-resistant materials: FG, WP, and TP. Through one linear fitting, it is found that their stress-fatigue life curves all present good linearity under the dual-logarithm coordinate system and have a high degree of fitting. Combining actual failures of the three test pieces during the test, it is proved that the complex containing TP has excellent adhesive effect with base materials and topping materials; that is, compared with complexes containing WP and TP, the complex containing TP has better fatigue durability and at the same time can effectively delay emergence and diffusion of cracks.

\section{Data Availability}

The data used to support the findings of this study are available from the corresponding author upon request.

\section{Conflicts of Interest}

The authors declare that there are no conflicts of interest regarding the publication of this paper.

\section{Acknowledgments}

The authors would like to thank the teachers and fellows of the TBM research group for providing help and at the same time thank the road test center and material testing center for providing the instrument.

\section{References}

[1] G. Qian, K. Hu, J. Li, X. Bai, and N. Li, "Compaction process tracking for asphalt mixture using discrete element method," Construction and Building Materials, vol. 235, p. 117478, 2020.

[2] F. Li and J. Xu, "Shear and fatigue performance of fiberglasspolyester paving mat for crack resistance," Journal of University of Jinan: Natural Science Edition, vol. 27, no. 2, pp. 212-216, 2013.

[3] Y. Chen, "Application of polyester glass fiber cloth in highway maintenance project," Science \& Technology Information, vol. 2011, no. 12, pp. 36-37, 2011.

[4] J. Qian, Y. Yao, J. Li, H. Xiao, and S. Luo, "Resilient properties of soil-rock mixture materials: preliminary investigation of the effect of composition and structure," Materials, vol. 13, no. 7, p. 1658, 2020.

[5] J. G. Qiao and P. Liu, "Study on the mechanical properties of interlayer bonding based on fiberglass-polyester paving mat," Science Technology and Engineering, vol. 16, no. 6, pp. 217-221, 2016.
[6] L. Cao, X. Q. Zhang, and Z. G. Li, "Research into the application of fiberglass polyester paving mat to mitigating reflective cracks in asphalt pavement," Defense Transportation Engineering and Technology, vol. 5, no. 1, pp. 70-73, 2017.

[7] J. Peng, H. J. Chai, L. Jiang et al., "Paving mat layers on testing section of chongqing circling expressway," Traffic Standardization, vol. 2011, no. 19, pp. 51-54, 2011.

[8] G. Zhou, R. K. Li, H. M. Wang et al., "Test on performance of reflective cracking resistance of warp knitting fiberglasspolyester paving mat," Chinese Journal of Highway and Transport, vol. 29, no. 2, pp. 16-22, 2016.

[9] C. Xue, "Distress prevention and treatments for reflection cracks or joint of new and old road surface used by polyester Bolivia filament cloth," Highway, vol. 2006, no. 4, pp. 225-228, 2006.

[10] C. J. Yi and P. C. Zhai, "Application of fiberglass-polyester paving mat in engineering," Advanced Materials Research, vol. 488-489, pp. 485-489, 2012.

[11] X. J. Cao, G. M. Li, J. Wang et al., "Bonding performance of fiberglass-polyester paving mat in humid climate," Journal of Chongqing Jiaotong University(Natural Science), vol. 32, no. 1, pp. 46-49, 2013.

[12] C. Yi and P. C. Zhai, Study on the Engineering Property of Fiberglass-Polyester Paving Mat, International Journal of Applied Physics and Mathematics, vol. 2, no. 2, pp. 73-76, 2012.

[13] J. Jin, Y. Tan, R. Liu et al., "Synergy effect of attapulgite, rubber, and diatomite on organic montmorillonite-modified asphalt," Journal of Materials in Civil Engineering, vol. 31, no. 2, Article ID 04018388, 2019.

[14] J. Gong, Z. Nie, Y. Zhu, Z. Liang, and X. Wang, "Exploring the effects of particle shape and content of fines on the shear behavior of sand-fines mixtures via the DEM," Computers and Geotechnics, vol. 106, pp. 161-176, 2019.

[15] R. David and I. V. Jones, TruPave Testing Methods-SuperPave IDT at, University of Florida, Gainesville, FL, USA, 2003. 